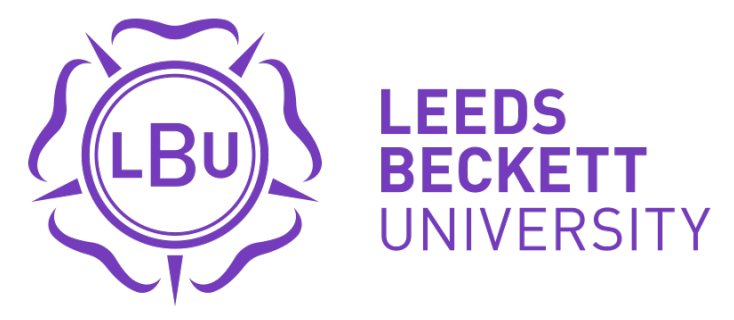

Citation:

Fisher, R and Fisher, P (2018) Peer education and empowerment: perspectives from young women working as peer educators with Home-Start. Studies in the Education of Adults, 50 (1). pp. 74-91. ISSN 1478-9833 DOI: https://doi.org/10.1080/02660830.2018.1520575

Link to Leeds Beckett Repository record:

https://eprints.leedsbeckett.ac.uk/id/eprint/4646/

Document Version:

Article (Accepted Version)

This is an Accepted Manuscript of an article published by Taylor \& Francis in Studies in the Education of Adults on 19 November 2018, available online: http://www.tandfonline.com/10.1080/02660830.2018.1520575

The aim of the Leeds Beckett Repository is to provide open access to our research, as required by funder policies and permitted by publishers and copyright law.

The Leeds Beckett repository holds a wide range of publications, each of which has been checked for copyright and the relevant embargo period has been applied by the Research Services team.

We operate on a standard take-down policy. If you are the author or publisher of an output and you would like it removed from the repository, please contact us and we will investigate on a case-by-case basis.

Each thesis in the repository has been cleared where necessary by the author for third party copyright. If you would like a thesis to be removed from the repository or believe there is an issue with copyright, please contact us on openaccess@leedsbeckett.ac.uk and we will investigate on a case-by-case basis. 
Peer education and empowerment: perspectives from young women working as peer educators with Home-Start

Roy Fisher*

School of Education and Professional Development

University of Huddersfield

Queensgate

Huddersfield

HD1 3DH

UK

r.fisher@hud.ac.uk

Orcid ID 0000-0002-9481-5117

\section{Pamela Fisher}

School of Health and Community Studies

Leeds Beckett University

City Campus

Leeds

LS1 3HE

UK

Pamela.I.fisher@leedsbeckett.ac.uk

Orcid ID 0000-0002-7121-5485

*corresponding author

Word count:

Abstract 224

Total 8,998 


\title{
Peer education and empowerment: perspectives from young women working as peer educators with Home-Start
}

\begin{abstract}
This paper focusses on peer education and specifically on young women peer educators working within the charity Home-Start in the north of England. This work is undertaken in a social context where educational achievement is increasingly measured by certification and occupational hierarchies have been 'professionalised' whilst notions of professionalism have been drained of meaning in ways which can be potentially democratising. State educational imperatives in the UK have focussed on concepts such as academic excellence and the promotion of vocational opportunities (for those from 'hard working families'). Within this paper the peer educator is positioned as generally similar to the individuals and groups with which they work in that they are likely to share characteristics including age, gender, ethnicity, social class, and educational attainment. The peer educators who participated in the study support each other in circumstances that lead to mutual benefits which are largely outside the educational mainstream. The paper considers motivations for involvement as a peer educator, peer educators' perspectives on the benefits/value of this work, the impact on confidence and aspiration, as well as their experiences of engagement and encounters with professionals. The paper, which focusses on empowerment, is informed by thinking on the importance of recognition and suggests that peer education holds potential for propagating forms of pedagogy which are relatively free of the authoritative relationships typically associated with 'teaching'.
\end{abstract}

\section{Keywords:}

Peer education; informal learning; social inclusion; empowerment; recognition. 


\section{Peer education and empowerment: perspectives from young women working as peer educators with Home-Start}

\section{Introduction}

Peer education is generally premised on democratic visions of knowledge acquisition and skill transmission and frequently works outside established education systems and institutions enshrined in stratified certification leading, at successive levels, to access only by appropriately qualified elites. The model of peer education which we consider below encapsulates the sharing of knowledge and skills in the context of a relatively informal community in which participants actively develop each other (as well as themselves). Democratic learning processes are important in the construction of the democratic citizen, and we see the 'flexible' capitalist production relations which are pervasive in developed economies as intrinsically damaging to both individual and social well-being (see Sennett 1999). In the UK, education has been seen as essentially about developing individuals who can be self-reliant as productive economic actors, and the education system is one which is both status conscious and institutionally hierarchical. This has, historically, provided relatively limited space within educational institutions for the accreditation of approaches to learning which are group based, non-hierarchical and which incorporate the largely feminist notion of an ethic of care (Gilligan 1982; Tronto 1993).

We are in a policy context which (still) contains the idea of meritocracy as both a 'good thing' and as a signifier of the 'good society' which, following recent UK policy pronouncements, is seen in some influential circles as best achieved by means of selective educational regimes through the revivification of grammar schools (May, 2016). Whilst this particular initiative is currently 'dormant', the thinking which kept it alive is potent more than fifty years on from its genesis in the politics of post-war social democracy. We shall argue not for education as a road to what we see as the myth of a meritocratic social order, but rather for some mitigation of this shibboleth through valuing and promoting peer education as a form of empowerment based on the notion of recognition (primarily as conceptualised in the work of Honneth 2001). Peer education, through its underpinning values and operational practices, has the potential to propagate alternative approaches to teaching and learning which stand 'outside' the traditional models of 'teacher to student transmission'.

Educational achievement is increasingly measured by certification, in the context of a society where mainstream political rhetoric speaks of equality of opportunity, offering the promise of social mobility, and social cohesion as the rewards for individual effort, ability and, in more recent times, resilience. Occupational hierarchies have been professionalised whilst the concept of what it is to be a professional, always a potentially oppressive formulation, has been drained of meaning by a combined proliferation of audit and regulation mechanisms (see Fisher and Fisher 2007). The ideology of neoliberalism and, in the UK, the hegemony of austerity based politics have combined to create a need for new forms of ameliorative social policy that can be operationalised outside the shrinking machinery of state funded social care (TaylorGooby 2013). Working class communities and identities have been transformed by the intensification of cultures of consumption, the breakup of traditional industries, and the global flow of labour (Standing 2014) as well as by cheap access to new technologies. Educational imperatives have tended to focus on concepts such as academic 
excellence for the more 'able', and vocational opportunities for those from 'hard working families'. Deeper conceptions of learning, commitment and achievement are largely unrecognised and unvalued by the state, remaining in the relatively invisible domain of third sector organisations, charities and at the level of community activism. This study, in recognising aspects of the social factors indicated above, focuses on young women working within a peer educator scheme operated in a town in the north of England through the charity Home-Start in order to highlight some experiences of involvement as a peer educator. It aims to contextualise thinking about peer education through a brief overview of some contributions to the literature on peer education, including the identification of conflicting views as to its utility, as well as to present evidence arising from participants in a particular peer education scheme.

\section{Informal learning and peer educators}

The benefits of peer learning, based often on cognitive psychology derived from the work of both Jean Piaget and Lev Vygotsky and their respective traditions, have long been recognised by educationalists (Damon 1984). It is, however, in a context of credentialism in employment and a tendency towards pedagogisation in higher education that the value of informal learning is often relatively unappreciated. Peer education, which we want to situate within the spectrum of informal learning, has had many adherents and proselytizers. This study highlights how a group of peer educators have worked together to support each other in circumstances that lead to mutual benefits which stand largely outside the educational mainstream (even where they may lead back into it). We are regarding the bulk of their learning as 'informal', though these particular peer educators benefited from participation in a peer educators' training programme operated by Home-Start on the basis of one day a week over nine weeks. This training programme covered 'getting to know Home-Start', equal opportunities, values and attitudes, confidentiality, listening skills/communication, commitment and boundaries, money, safeguarding, drugs misuse, relationships and sexual health, personal safety, domestic violence, and smoking cessation. Our focus, however, was on the experiences and feelings of the peer educators in relation to being a peer educator and through the various engagements which that role entails, including the interactions with other peer educators and with Home-Start employed staff, which take place outside the processes of training and which arise primarily from the consequences of recognition (improved confidence and self-esteem, higher levels of motivation, the acquisition of new knowledge and skills) which the role endows on participants.

Harden, Weston and Oakley (1999) undertook an extensive review based on 462 English language studies of peer delivered health promotion for young people, finding 'some evidence' to support the effectiveness of peer education in that context but concluding that 'methodologically sound studies were disappointingly scarce' (p. 3). In the same year, Turner and Shepherd (1999) referred to peer education as a 'method in search of a theory', a characterisation which was by no means unfair at that time and which remains substantially true. They attempted to apply social learning theory, social introduction theory, role theory, differential association theory, sub-cultural theory, and communication on innovation theory to health related peer education programmes, specifically in relation to a range of frequent rationales for the use of peer education. Their study concluded that 'whilst most theories had something to offer 
towards an explanation for why peer education might be effective, most theories were limited to particular claims, and with regard to such claims, limited empirical evidence is available.' (p. 245).

The concept of 'peer educator' is one which is used in a range of ways and which it is therefore important for us to clarify and, in particular, to provide a rationale for our favoured conception of the role. Peer educators, often based in educational institutions, have long been a feature of social and health education, especially in the USA (Brack, Millard and Shah 2008). Shiner (1999) pointed to difficulties around definition, the term 'peer' having often been used in relation to delivery by health professionals and (even) in relation to teaching undertaken by trained teachers. Some studies utilise the term 'near peer' to describe circumstances where there are status differentials (for example, Khaw and Raw 2016). Through a review of a number of UK projects Shiner (1999) points to a need for clarity regarding what 'peerness' means. Given the wide range of factors that might denote 'somebody like us' Shiner argues that, certainly in relation to peer education theory, the key factor is that of 'age' although this does not constitute a 'master status that overrides all other possible sources of identity' (p. 558). Shiner highlights the significance of aims and methods in relation to peer education arguing that peer education is '...primarily viewed as a method of delivery' (p. 559), something which is reflected in the various terms used in relation to peer workers. Shiner suggests that the themes of peer development and peer delivery are useful in considering the nature of peer involvement in a particular project (p. 560). Burdette Williams (2011) discusses the trajectory of peer education within American higher education, seeing peer educators as part of the changing nature of the HE cohort (more mature, more part-time), and their prevalence as a consequence of the move from teaching centred to learner centred pedagogy. These demographic trends have been present in the UK following expansion of the HE system (Bathmaker 2003). Stigmar (2016), in a review of thirty studies discussing peer tutors working to complement university teachers (mostly in the US and UK), refers to expanding student numbers and reduced resources as the context of peer education initiatives in HE. Within HE, as might be expected, peer tutoring is typically a device deployed by tutors and is an adjunct to a range of more formal approaches to teaching/learning. Stigmar concludes that there are pedagogical advantages which arise from peer education, finding that that generic skills and metacognitive development improve through access to peer-led teaching, though he was unclear as to whether deep level learning was stimulated.

Burdette Williams, writing specifically in relation to the US context, sees the rise of peer education as part of a need to save costs, arguing that peer educators can provide 'critical assistance' to a 'high quality, educated professional workforce' and that they can do this 'at a fraction of the cost' (p. 2). Contrary to this view, our own conception of the peer educator is based on a democratic ethos which does not privilege the peer educator and which, at the same time, does not set them in contradistinction to 'high quality educated professionals'. We see the peer educator as one who is generally similar to the individuals and groups with which they are working in the sense that they are likely to share characteristics that would include some (but by no means all) of the following: age, gender, ethnicity, social class, educational attainment, parental status, specific social categories which may be applicable in 
relation to sexual orientation, and, in some instances, the use of alcohol and substances. This could be conceptualised as a form of 'pure peer-ness'. It is, perhaps, interesting to note that in the world of computer networks a 'pure' peer-to-peer network is one where all nodes possess equal ability/capacity. This returns us to Shiner's (1999) notion of 'somebody like us'. The key factors, we suggest, are the principle method of 'delivery' for the associated learning processes, the nature of the peer relationship (which is normally derived from the particular scheme and/or context in which the peer educator is working), and a high degree of 'peerness' between those involved. We see these characteristics are central to the notion of peer education whatever the context, and we are firmly committed to the recognition of educative processes which take place outside designated educational institutions.

\section{Some issues with peer education}

As Smith (2012) has pointed out, it is important not to see pedagogy as limited to 'teaching' or pure didactics. Broader understandings of pedagogy might make debates surrounding peer education less contentious than they have hitherto been. Frankham (1998) has pointed to an 'almost religious tenor' in discourse about peer education with claims which are 'overstated' or 'disingenuous' (p. 179) and, she argues, with some peer education conferences reinforcing it as a 'self-validating enterprise' ( $p$. 181). Frankham, having conducted an evaluation of a peer education project relating to HIV prevention, was drawn to investigate some of the claims made by proponents of peer education. Through her review of the literature she found little evidence that conversations between peers about sex lead to any learning. Indeed, she found evidence that 'peer pressure'/influences on young people '... may have been greatly exaggerated, in some contexts'. (p. 186). Based on her work in evaluating peer education she found that young people were drawn into being a peer educator primarily for the purpose of their own learning or to build their own curriculum vitae and that the peer educators themselves may well be the primary beneficiaries of their efforts. She also fears that the role can place peer educators in 'an invidious position'. (p. 190) in which they are called upon to pronounce on issues when not qualified to do so. Further issues arise from being positioned at the intersection of professional and peer cultures, and from the contradictions around what participants in peer work are supposed to accept or resist.

Southgate and Aggleton (2017) have insightfully encapsulated some key issues which have afflicted academic studies of peer education. One of these is that the associated literature has generally focused on '... measuring the initial outcomes and downstream impacts of the approach...' (p. 4) and that there has been a lack of evidence in support of the effectiveness of the approach. They identify a technicist interpretation of education, lacking the theoretical sophistication necessary to provide an adequate account of the complex processes of peer education, as one of three problematics. A second problematic, they contend, is a 'black box approach' so considerations of peer education frequently measure inputs and outputs but fail to examine '...socially mediated processes between learners (and educators) entering the educative moment...' (p. 6). A third problematic is the limited attention given to the social dynamics '....inherent to educative processes such as ethical and power relations, the role of emotion and embodiment, and the evocation of tacit knowledge or practical wisdom...' (p. 6). This, they argue, places a focus on who the peer is, and the extent to which they embody the correct qualities for the specific context of their work. 
Southgate and Aggleton point to a need for conceptions of pedagogy that are informed by critical theories of power relations and authority and which thereby have the capacity to create frameworks with the capacity to properly analyse peer education. This study is not on a scale that seeks to remedy the three problematics identified by Southgate and Aggleton, it does, however, hope to present some evidence of the ways in which peer educators can be empowered by reference to a specific instance within Home-Start.

\section{Home-Start}

The peer educator scheme which provided the site for the empirical component of this study is one operated within Home-Start, an international family support charity which was founded in Leicester, UK in 1973 by Margaret Harrison (1938-2015). Home-Start supports parents through volunteers who are parents. In the UK Home-Start has approximately 16,000 volunteers working to support 30,000 families - there are 261 local Home-Starts. Home-Start now operates in 22 countries across five continents and is rooted in local communities to support parents to overcome a range of challenging circumstances. Home-Start provision involves diverse forms of emotional and practical support some of which is provided by volunteer peer educators who have themselves experienced difficulties that can arise in relation to early and/or unplanned pregnancy, and who have usually been the recipients of Home-Start services (HomeStart 2016). This approach is based on developing individual and collective forms of resilience within often disadvantaged communities in which young mothers may face a range of social, economic and emotional challenges.

Home-Start works through home visits in which volunteers with child care experience support families with young children. The youngest child must be under the age of five. Families and mothers who are new to parenting or who have limited social support networks are the usual recipients of Home-Start support and participation is voluntary. Home visits are normally undertaken once a week and they seek to provide emotional support as well as help with establishing household routines. The Home-Start volunteers provide encouragement whilst informally modelling child care behaviour. We shall briefly refer to some key studies of Home-Start in order to provide appropriate context to the present study of peer educators. Work undertaken in the Netherlands by Dekovič et al. (2010) showed that Home-Start enhanced the sense of maternal competence and supportive parenting whilst reducing the use of 'inept discipline' ( $p$. 271). Building on the same Dutch study, Hermanns et al. (2013) followed three groups of families over four years and found that those working with Home-Start showed more positive changes in parental well-being, competence and behaviour than two other groups of 'non-Home-Start' families studied, reporting that 'the findings of the study seem to contradict current views that interventions in the early years of life should by necessity be focused, highly structured and delivered by professionals'. (p. 682). This work was followed up by van Arr et al. (2015) who found that Home-Start's work contributed to positive short term changes which were sustained longer term.

In the UK Frost et al. $(1996 ; 2000)$ undertook a three year study of Home-Start based on a survey of 305 families and semi-structured interviews with 46 households $-61 \%$ of the families were 'economically inactive' and $54 \%$ were 'lone parent families'. Many (almost two thirds) faced health related issues including mental health. $61 \%$ of the families faced 'parenting difficulties' and '....in three quarters of the families there were 
issues relating to the confidence and self-esteem of adults, mainly mothers.' (Frost et al. 2000 p. 330). Home-Start was seen as a flexible, non-stigmatising service which was complementary to statutory services whilst filling something of a gap between health and social services by providing support to those who, when maternity related support is discontinued, might not qualify for social care intervention (Frost et al. 2000 p. 331). Frost et al. found that, over a six month period, $64 \%$ of the sample saw an improvement in emotional well-being, $55 \%$ saw an improvement in their informal networks, $51 \%$ saw an improvement in parenting issues (with 6\% reporting a deterioration). $37 \%$ reported an improvement in their relationships with professional workers, whilst $21 \%$ reported that these relationships deteriorated. In a study based in Peterborough, UK Akister et al. (2003) identified that of the issues which concerned the parents involved those of behaviour management, school bullying and family relationships were strongly represented. The study found that parents valued the relationship with their Home-Start volunteer and 'some enjoy the group experiences which offer contact with other parents in similar situations to themselves.' (p. 29).

McAuley et al. (2004) studied 12 Home-Start schemes in Northern Ireland and eight in Southern England involving a total of 80 families receiving Home-Start interventions as well as a comparison group of 82 families. Maternal depression was high in both groups at the point of referral. The study used questionnaires as well as interviews. Four fifths of the Home-Start mothers felt that the Home-Start volunteers relieved their pressures. According to Underdown (2005), however, the report from McAuley et al. (2004) offers no evidence that Home-Start is effective or cost-effective in relation to parent-infant relationships. Themes drawn from interviews with the mothers were pregnancy/birth trauma and mothers' well-being post birth; transition to parenthood; multiple demands of young children on one adult; lack of available support and need for respite; mothers' mental health; parenting a child/children with special needs and/or behavioural problems; mothers' physical health/disability; financial worries; mothers' relationship with ex-husbands/ex-partners; mothers' self-esteem; children's wellbeing and social support.

\section{Methodology}

What the above studies show is that Home-Start interventions are generally positive in their impact, and that they operate in complex social spheres where a range of familial, domestic, medical, economic and social factors coalesce and collide. It is in this demanding context that Home-Start workers, including peer educators, are interacting, learning, and developing and contributing their individual and collective expertise.

This study involved the completion of questionnaires by eight Home-Start peer educators, and the conduct of a focus group (which is the source of all peer educator quotations in this study) comprising five Home-Start peer educators and a Home-Start worker, an interview with a Home-Start worker, and a telephone interview with a Home-Start peer educator. The 'Home-Start worker' was a paid employee with the role 'group co-ordinator' and was part of a small team of employees based at this HomeStart Scheme. All the peer educators were volunteers who had taken on this role at the same local Home-Start in the north of England after benefiting themselves from Home Start peer and group based support. The individual identities of the peer 
educators and Home-Start workers have been anonymised with pseudonyms used in all focus group extracts which appear in this study (the use of pseudonyms also applies were the names of peer educators' children are mentioned). Participants received a participant information sheet via Home Start management in advance of the focus group/interview. This made clear that the decision to participate was entirely voluntary, and that there would be no negative consequences of declining to participate.

Our approach to this study was one which sought to recognise and respect the sensitive network of relationships established between Home-Start employees and the volunteer peer educators, as well as between the peer educators themselves. Initial approaches to the peer educators were undertaken indirectly via a Home-Start employee ('group co-ordinator') with the intention of building confidence and making it easier for potential participants to decide whether or not to be involved with the study. Individual peer educator details (such as prior educational performance) were collected in advance again through Home-Start. This was in order that a focus group could be devoted to discussion of participants' experiences of, and feelings about, their roles as peer educators. Data collection (excepting individual interviews) was undertaken in the context of the regular peer educator group meetings and in the usual location (the local Home-Start premises). The focus group and the peer educator telephone interview were conducted by the female co-author of this paper, an approach we considered important given the nature of the peer educators and their work. Transcripts of the focus group and interviews were analysed for key themes and it was from this process that empowerment and recognition were identified as key issues.

The eight peer educators who completed our survey ranged in age from twenty to twenty-four with an average age of 22. Seven were white British and one of mixed white and black Caribbean ethnicity. One had a declared disability (dyslexia). All but one were lone parents. One was in full-time employment as a care assistant, another was employed part-time as a hairdresser, another was a student. The rest were either not in employment or did not respond to the question related to employment. Only one had no formal qualifications, five held 5+ GCSEs at grade $A$ to $C$ and two of these had two or more GCE A levels. The shortest period of time working with and supported by Home-Start was eighteen months and the longest was six years. One was currently training to be a peer educator and the rest had experience in that role ranging from one year to three. Five had one child, two had two children, one had one child and was currently pregnant. The average age of their children was 3 years. We are unable to say how typical these profiles are for the young women that become part of a HomeStart project, but it seems reasonable to assume that the peer educators are likely to be those who have responded most positively to the benefits that Home-Start provides, and that they are those who have the abilities, and the social circumstances and resources, as well as the motivation and well-being to enable them to 'give something back'.

\section{Motivations for involvement as a Home-Start peer educator}

The motivations involved in choosing to become a peer educator are inevitably complex and variable, though given the (in this instance and in many others) voluntary nature of the work the contributions of time and energy are indicative of altruistic values 
and a strong commitment to others. One peer educator in this Home-Start project commented that,

...I do enjoy coming and speaking to everybody and just helping people as well. Like l've worked in the groups and l've also worked one-to-one with some mums as well, doing things like [...] sorting out housing or like [...] college applications and things, and just being a support for other people has been, it's quite rewarding.

There are also some more instrumental motivations. Another peer educator, echoing one of Frankham's (1998) points above, had become involved through a wish to enhance her application to higher education,

....applying for university I needed a hundred hours voluntary work, and they put me in touch with Home-Start [...] So l'd asked if I could be part of it, and I did all my training and everything, and I had a plan to do like my hundred hours and l've been here [...] two years now [laughter in group].

Our sense is that the participants in this study strongly valued their participation in a community with a social purpose, and that there was a sense of helping others whilst helping the organisation that had supported them. Being a peer educator is a way of promoting personal and objectives whilst simultaneously enhancing the lives of others.

\section{Relations with professional workers}

A key element of the work of a 'pure' peer educator ethos is that of 'peerness' - that is that the relationship is not hierarchical. Relationships between clients/service users and professionals are inevitably laden with power relations and these are often amplified by factors such as age disparities and other aspects of positionality. The focus group which participated in this study became particularly animated when discussing their encounters with professionals. One peer educator remarked that, 'A lot of people turned around to me and said "how are you supposed to look after a child when you're still a child yourself? You know, 'you can't do anything for yourself".' Another recounted an incident when her two year old was rushed to hospital having swallowed a coin, 'The whole time we were there, I lived with my mum at the time, everybody spoke to my mum, and it absolutely riled me. And in the end I were like "you do know I'm this child's mother? I might be eighteen but I am her mother. So if you've got something to say can you speak to me please, not to my mum".' Another felt that she had been 'treated awfully in the hospital when I was having my son.' Another agreed 'It were awful in hospital, I had the worst experience.' Another felt 'People are right quick to dismiss you.' One peer educator stated,

I'll be honest, I was on a Child in Need plan with social services when I started coming here and one of the - they have like criteria and one of the criteria was for me to attend Sure Start, and I said 'I'm not going, l've been once and I had an awful experience'.

It was explained that, 
And like being so young, obviously, you get judged a lot and stuff, and I found that really difficult to deal with, but just coming to the group and knowing that everybody's in the same situation and that you're not alone, that helped.

Fisher (2007 p. 584), in relation to parents of disabled babies, has argued that their "... attempts towards the construction of their own wellbeing are being undermined by their contact with the health and social care services where they are confronted with oppressive frameworks of meaning that attribute 'damaged' identities to them and their children whilst failing to recognise their particularity and authenticity." Fisher applies the work of Honneth $(2001,2003)$ to argue that identities are formed intersubjectively and that misrecognition arises through the application of normative frameworks. Parents' experiences within family contexts may well contribute to the construction of authentic and meaningful narratives of wellbeing but these are sometimes not validated in encounters with professionals which tend to emphasise 'expert' ways of knowing and interventions. Peer educator relationships very largely, often wholly, remove the symbolic violence and sense of stigma which is sometimes enacted in professional/client interactions (Thapar-Björkert, Samelius, and Sanghera 2016), enabling the participants to develop recognition for their experiential expertise which crosses private/public boundaries. One peer educator explained that,

...this is why this peer educator project works so much, because I know when I was pregnant, or when I'd just had Emma, to speak to somebody who hadn't been a teenage parent, or hadn't even been a parent, and you feel very like, they speak to you very patronising, you know, and it's all very textbook. You know, 'this is what you do' or 'this is what you don't do', 'this is how you should feel. This is how you shouldn't feel.' So the peer educator programme really does work because everybody here has been a teen parent.

\section{Peer educators' views on the benefits/value of involvement in this work}

The peer educators were very much aware of the ways in which they had personally benefitted from their involvement in this work and from the associated training. One peer educator stated that,

[...] it's helped me loads [...] coming and doing the training here in so many different things like has even helped me as a parent, you know, and thinking about the ways we are trained to deal with situations has helped me later down the line to deal with my own situations.

Another encapsulated the way in which their engagement with Home-Start had been transformational,

I went through a bad relationship about six months ago, and I got all my support through Home-Start, like benefits, having to go find a house, everything. That's helped me do that. And then because of that I came out a better person, and then she asked me if I wanted to do the peer educator training.

An interaction within the focus group was redolent of the mutual support provided: 
Susan And we've all been there with them kind of [bad] relationships, but as soon as she started to change her life it were like we finally saw Debbie. Debbie appeared (laughter). We always knew she were in there but it were just trying to pull her out, and it's, it were like a million weights had been lifted off her shoulders....

Jacqui Yeah.

Susan She started smiling all the time and just enjoying life. You could see it....

Debbie $\quad$ You'll get me crying so shut up (laughter).

Jacqui Shall I get some Kleenex?

Debbie I'm alright (laughs).

Susan No but I mean to be able to pass that on, as well, to other parents, what you've been through, and look at you now. It's inspirational.

It was clear that learning for the peer educators went well beyond their training sessions and that much of it arose from their informal interactions with each other,

...the practical side of it really helped [...] it was stuff like thinking that l'd not done stuff right. So, l'd be at home with her and l'd panic, and then l'd come to [the] group and l'd be like 'oh John did so-and-so, so-and-so and they'd all be like 'oh that's fine, my baby does that too', and I thought 'oh does it?' [laughter] You know, just the relief of knowing that you're not actually a bad parent.

The sense of being part of a peer community was simultaneously supportive and empowering. The peer educators spoke about their ability to communicate more openly with their peers,

I had a family nurse and she were lovely... and I'm still in touch with her now, but I just think you...do open up and speak to somebody closer to your own age, you just do...you let your guard down and you forget about, you know, that...it's like talking to one of your own friends.

Being a peer educator was a factor in building confidence through a sense of achievement, as the contributions below (each from different peer educators) indicate

I'll stand there and say, not go into great detail about what you've been through, but just say 'I were in a bad relationship' [...] But for you to be able to stand there and say that, even if that can hit home with somebody it'll make them think twice, you know? 'Oh God I'm in a bad relationship. You've got out of it [...]', it's, that's the sharing information about yourself and standing there in front of other people, especially that you don't know, it's just huge.

The counsellor [...] referred me here and, I can't even, they've just done so much for me like with my confidence, in terms of like I was so shy when I first came again [laughs] and um yeah just with baby stuff as well like and being 
around the other young mums and hearing their stories. Like if I ever had a problem I could just come to group and there'd be somebody else in that group that would have had that same problem...

[...] I've had to build my confidence back up, and Home-Start has been a massive part of that.

I think I was spiralling into depression when I were in my relationship, and I think getting me out of it has just, I think l'd have hit rock bottom if l'd have carried on. [...] if I hadn't come to Home-Start...

The formal training aspect was also strongly appreciated,

...they told us how to talk to your children about, you know, what you should tell them at what age and things like that, and my daughter could probably teach a class now [laughter]. But that training were really good because then we went on to do some things in college [...] some sexual health like awareness sessions...?

Um sex education, first aid, all them stuff. Doing all them and then getting my certificates, because I never went to college. Well I went for a bit but then I just quit because I'm a quitter [laughter...]. So doing all that, it were kind of like an achievement, you know, like, it sounds stupid to say it but to, just to realise that I'm not just a mum. I'm not just somebody's mum and I don't have to sit at home all day watching CBeebies and changing nappies. And now, I look at me now from seven years ago, and now I have two jobs, you know, I work forty hours a week...When I got upset about something it affected the kids because I wouldn't, you know, be as involved with them because l'd be too wrapped up in my own problems and l'd just be silent. l'd be like, you know, I can't be bothered doing anything, and now I'm like the complete opposite, I'm like 'right kids, what are we doing? Let's just do something', you know? [...] I feel like a stronger person now....

The training was not only a means of becoming a peer educator, but also had benefits in relation to developing strategies that could be deployed in everyday interactions.

\section{Impact on life plans and aspirations}

The experience of working as a peer educator had clearly positively influenced life choices and aspiration,

...a lot of it is just knowing what to do in those situations and having the confidence to do it. But in terms of like education and everything, originally I was going $[\ldots]$ to do a social work degree um (coughs) unfortunately I got just below what I needed to get on the course and changed to Behavioural Sciences and I carried on here, but through working with the social services and everything here and seeing what the girls have been through and everything I 
actually decided that that's not the route I wanted to take [...] I've got a lot of interest now in child psychology...

For one young woman, working as a peer educator constituted a developmental activity in what she saw as a break from formal education which enabled her to focus on her son,

I went straight back to college when John was five weeks old, finished with a distinction star, so. [...] And got into uni from there, so [...]. I went to uni for a year but decided to defer it because I was missing out on too much with my son [...] but the plan is to go back to uni, but when he's a little bit older.

For another the peer educator role with Home-Start had proven a platform to joining a college course,

I'm starting college this September as well and I wouldn't be able to do that without Home-Start either, getting back into education and doing what I want to do [...] I probably wouldn't have known about the course because Jenny did it and that's kind of how I knew there were an access to nursing course.

For some the commitment to their peer educator role was seen as long term,

I think I'll be here until either I physically can't be or they kick me out [laughter...] I do really enjoy it, and it's like through uni you, Julie [Home-Start worker] always says to me 'are you sure it's not too much?' I'm like 'no I'm doing it. I'll just have to work everything around and just do it [...]

...l'd love to [carry on in the role], just because Home-Start have done so much for me and I would not be here, I would not be the person that I am today if it weren't for Home-Start.

For some the horizon was to achieve financial stability and some material objectives,

Yeah, I want to go in Child Behavioural Psychology, and I want like a mortgage and a car and to have Gemma [her child] just think I'm ace [laughter] doing all this. Er I just want to be stable and settled and, like I don't wish for much more than that really...

I want a mortgage [...] It's taken me five years to get good credit so, I'm adamant. I don't know how I'm going to do it, I'll rob a bank but I'm going to get a mortgage [laughter]. No not loads of stuff. Like I want a better car which isn't a massive goal, and I want to take my kids to Disneyland. That's definitely happening...I want to be senior carer at work. That should only take me about a year, rapid. Hopefully somebody'll quit before then (laughter) and I'll get in there and do that. 


\section{Discussion}

Frawley and Bigby (2014 p. 172), in an Australian based study of a 'respectful relations programme', found that the (disabled) peer educators they studied talked about 'helping others', feeling 'credible' in relation to their knowledge and experience, being 'role models', and 'developing their own knowledge and skills'. There was, importantly, a '...sense of empowerment from their involvement...' and this was the key finding from our own study. Empowerment, as Turner and Shepherd (1999) noted, is a concept which is difficult to evaluate. They identify social learning theory (Bandura $1977 ; 1986)$ as having particular purchase in relation to explaining empowerment through peer education, though we feel that it lacks the explanatory power to account for learning in complex social formations. It was clear that the peer educators in our study believed that they had greatly benefitted from their involvement in such work, and in particular that they had gained confidence, and that this had been a spur to move forward with their lives in a positive way. Being empowered is, we argue, partly an internalised feeling or disposition towards the world but also, in a more complex way, partly about external (to the individual) reactions and the implications of these for self-efficacy. The concept of empowerment can be articulated in many ways, and there are difficulties in relation to the extent to which educative processes might lead to empowerment, and especially so when gender is a factor. Monkman (2011) outlined Stromquist's $(1995,2002)$ model of empowerment which is based on four dimensions as follows:

'- the cognitive (critical understanding of one's reality)

- the psychological (feeling of self-esteem)

- the political (awareness of power inequalities and the ability to organize and mobilize), and

- the economic (capacity to generate independent income).' (p. 5)

The Home-Start peer educators who participated in our study showed clear and compelling evidence of substantial progress in relation to the first two of these four dimensions. There was also a sense that, at the micro level of everyday interactions, and particularly within familial relationships, a form of political empowerment had been achieved. Our study, quite deliberately, did not focus on the issue of capacity to generate independent income though some evidence of this was apparent ("...people said to me 'oh you'll never be able to work' and it's like now I work two jobs, I make money. They always said l'd never have any money, but now l've got money.").

It was the New Labour governments which, between 1997 and 2010, enacted policies based on notions of empowerment through the citizen as a reflexive agent, an approach which the Conservative component of the Coalition Government (20102015) which followed it would seek to capture in the ethos of the 'Big Society' (which can be characterised as a form of conservative communitarianism and 'self-help' through resilient individuals). In this worldview parenting is conceptualised as a form of occupation based on the application of skills which can be both improved and regulated by reference to expert professionals, all in a framework of economic wellbeing based on engagement with paid employment. As Fisher (2007 p. 585) has pointed out, within policy discourses the '...notion that life within the private sphere may also provide the basis for self-esteem and wellbeing and be seen as a hallmark of participation is conspicuously absent.' 
Intersubjective recognition enables the development of the reflective competent citizen actor (Sointu 2006) who is able to attain the positive 'practical-relation to self' (Yar 2001 p. 299) which is a basis for self-empowerment. Recognition is a prerequisite for agency. Honneth $(2001,2003)$ argues that recognition is institutionalised in three spheres of life: these are 'love' (intimate relationships), the 'legal order' (equality in law) and 'achievement' (gained when through self-esteem derived from abilities that are respected and valued). All three of these domains are dependent on recognition by others. 'Love', according to Honneth $(2003,2006)$, is gained primarily through the private sphere (family and friends). 'Achievement' follows success in the public sphere (jobs/career). As argued elsewhere, "Misrecognition may be attached to social marginalisation through socio-economic circumstances, religion and or disability (of the parent) and parents who simply lead unconventional lives are likely to be subjected to normalising judgements and the exercise of 'disciplinary power'... relating to ideas of 'good enough mothering.'...the risk management agenda within health and social services is also contributing to processes of misrecognition by an over-zealous policing of people's lives... linked to an increasing tendency to perceive individuals' 'needs' for resources and services in terms of personal failings..." (Fisher, 2007 p. 593).

Whilst Honneth's analysis $(2001,2003)$ is premised on a separation of private and public realms, the testimonies of the participants in this study suggest that the peer educator project provides recognition across these boundaries. This appears to be one of the strengths and hallmarks of peer support when compared with traditional 'professionalism'.

Nancy Fraser (1997) argued that that those who belong to socially excluded groups should resist through the development of 'subaltern counterpublics' (or discursive arenas) and thereby construct oppositional identities and interests around 'counter discourses'. Elsewhere, in a consideration of auto-didactism amongst parents of disabled babies (Fisher and Fisher, 2007), it has been argued that this process is being enacted through cyber-communities leading to subtle shifts in power away from professional expertise and the development of expertise through the sharing of experiential knowledge acquired in the domestic sphere. Utilising the Granic and Lamey's (2000) conception of the Internet as 'a self-organising system' with the potential to 'catalyse major shifts in the cognitive styles and beliefs of its interactants' (p. 94) regular internet participation might well change cognitive patterns and build confidence/expertise and the development of non-binary worldviews. Our sense in relation to this group of non-virtual peer educators was that the sheer viscerality of working with others in person and in the present was a key part of the transformational processes from which they had benefitted.

\section{Conclusion}

I'm really busy all the time [...] I feel like, like Wonder Woman, like I can do anything now like. I can't possibly go through any more shit in my life. I can just do anything. But having people to talk to [...] with peer educating, helping other people, and now I feel like because I've been through that much, I can tell people 'you're going to be alright'.

[Home-Start peer educator] 
The peer educators who participated in this study are engaged in the active construction of their relationships with their families and children, friends, and other users of the services provided in ways that link with their rights of recognition and which provide a tangible sense of empowerment. This is achieved through valuing individual particularity and authenticity through processes of group solidarity. In doing this, they are also challenging discourses around education and wellbeing.

Lingard (2005) has discussed uses of pedagogy which "...challenge the modernist provincialism of an 'education-bound' conception of pedagogies, as well as challenging the salience of contemporary education and its traditional pedagogies...There has historically been a broader usage of pedagogy than simply within institutionally confined education." (p. 167-8) He concludes that "The policy and social conditions that inhibit the instantiation of productive pedagogies in schools have been traversed, as have the challenges from the breaking out of pedagogies from specialist educational settings.' (p. 183). We see pure forms of peer education as generally situated outside educational institutions, though not necessarily so, and as propagating forms of pedagogy which are relatively free of the authoritative relationships that are typically associated with 'teaching'. According to Honneth (2001, 2003) the human dependence on intersubjective recognition needs to be realised in both the private and public domains of life. In the private sphere, parents are able to construct counter-hegemonic understandings that enable them to develop relationships in which they both gain and provide recognition based on affection and love. The refusal of recognition in the public sphere must be addressed by education and by health and social services. The hegemonic grip of capitalist modes of thought has followed new modes of production and consumption. Structural issues in society are mirrored in education and, we suggest, education has potential for resistance and transformation by embracing different modes of delivery. Peer education, at least in some of its forms, and despite the critiques it has faced, presents one such possibility.

\section{Bibliography}

Akister, J, Johnson, K. McKeigue, B and Ambler, S., 2003. Parenting with Home Start: users' views, Practice, 15 (1), 21-32.

Badura Brack, A., Millard, M., and Shah, K., 2008. Are peer educators really peers? Journal of America College Health, 46 (5), 566-568.

Bathmaker, A.M. 2003. The Expansion of Higher Education: A Consideration of Control, Funding and Quality In: Bartlett, S. and Burton, D. (eds) Education Studies. Essential Issues, London: Sage, 169-189.

Bandura, A. 1977. Social learning theory. Englewood Cliffs, NJ: Prentice Hall.

Bandura, A. 1986. Social foundations of thought and action: A social cognitive theory. Prentice-Hall, Inc. 
Burdette Williams, L., 2011. The ongoing, and emerging place of peer education, In: L. Burdette Williams, L. ed. Emerging Issues and Practices in Peer Education: New Directions for Student Services, 133, 1-6.

Damon, W., 1984. Peer education: the untapped potential. Journal of Applied Developmental Psychology, 5, 331-343

Dekovič, M., Asscher, J. J., Hermanns, J., Reitz, E., Prinzie, P., van der Akker, A. L., 2010. Tracing changes in families who participated in the Home-Start parenting program: parental sense of competence as mechanism of change, Prev Sci, 11 (3), 263-274.

Fisher, P., 2007. Experiential knowledge challenges "normality" and individualised citizenship: Towards "another way of being". Disability and Society, 22 (3), 283/298.

Fisher, P. and Fisher, R., 2007. The 'Autodidact', the Pursuit of Subversive Knowledge and the Politics of Change', Discourse: Studies in the Cultural Politics of Education, 28 (4), 515-529.

Fisher, P. and Goodley, D., 2007. The linear model of disability: mothers of disabled babies resist with counter-narratives. Sociology of Health and IIIness, 29 (1), 66-81.

Frankham, J., 1998. Peer education: the authorised version. British Educational Research Journal, 24 (2), 179-193.

Fraser, N., 1997. Justice interruptus: Critical reflections on the 'post-socialist condition'. London: Routledge.

Frawley, P. and Bigby, C. 2014. "I'm in their shoes": experiences of peer educators in sexuality and relationship education. Journal of Intellectual \& Developmental Disability, 39 (2), 167-176.

Frost, N., Johnson, L., Stein, M. and Wallis, L., 1996. Negotiated Friendship. Leicester: Home-Start UK

Frost, N., Johnson, L., Stein, M. and Wallis, L., 2000. Home-Start and the delivery of family support, Children and Society, 14, 328-342.

Gilligan, C. 1982. In a different voice: Psychological theory and women's development, Cambridge, MA: Harvard University Press.

Harden, A., Weston, R. and Oakley, A. 1999. A review of the effectiveness and appropriateness of peer-delivered health promotion interventions for young people. London: EPPI-Centre.

Hermanns, J. M. A., Asscher, J. J., Zijlstra, B. J. H., Hoffenaar, P. J., and Dekovič, M., 2013. Long-term changes in parenting and child behaviour after the Home-Start family support program, Children and Youth Services Review, 35, 678-684. 
Home Start, 2016. About Us. https://www.home-start.org.uk/about-us accessed 6 November 2016

Honneth, A., 2001. Recognition or redistribution? Changing perspectives on the moral order of society, Theory, Culture and Society, 18 (2-3), 43-55.

Honneth, A., 2003. Redistribution as recognition: a response to Nancy. In N. Fraser and A. Honneth Redistribution or Recognition? A Political-Philosophical Exchange. London and New York: Verso.

Khaw, C. and Raw, L., 2016. The outcomes and acceptability of near-peer teaching among medical students in clinical skills. International Journal of Medical Education, 7, 188-194.

Lingard, B., 2005. Socially Just Pedagogies in Changing Times. International Studies in Sociology of Education, 15 (2),165-186.

McAuley, C., Knapp, M., Beecham, J., McCurry, N. and Steed. M., 2004. Young families under stress: outcomes and costs of Home-Start support. York: Joseph Rowntree Trust.

McIntyre, A. 1999. Dependent rational animals: why human beings need the virtues, London: Duckworth.

May, T., 2016. Britain, the great meritocracy: Prime Minister's speech. London: DfE/PM's Office. https://www.gov.uk/government/speeches/britain-the-greatmeritocracy-prime-ministers-speech accessed 24 March 2017

Monkman, K. 2011. Framing gender, education and empowerment. Research in Comparative and International Education, 6 (1), 1-13.

Rose, N., 1999. Powers of freedom. Cambridge, England: Cambridge University Press.

Sennett, R. 1998. The corrosion of character: the personal consequences of work in the new capitalism, New York: Norton.

Shiner, M., 1999. Defining peer education, Journal of Adolescence, 22, 555-566.

Smith, M. K. 2012. 'What is pedagogy?', the encyclopaedia of informal education. [http://infed.org/mobi/what-is-pedagogy/. Retrieved: 20 October 2017].

Sointu, E., 2006. Recognition and the Creation of Wellbeing, Sociology, 40 (3), 493510.

Southgate, E. and Aggleton, R., 2017. Peer education: from enduring problematics to pedagogical potential Higher Education Journal, 76 (1), 3-14.

Standing, G., 2014. The precariat: the new dangerous class. London: Bloomsbury. 
Stigmar, M. 2016. Peer-to-peer teaching in higher education: a critical literature review. Mentoring \& Tutoring: Partnership in Learning, 24 (2), 124-136

Stromquist, N. P. 1995. Theoretical and Practical Bases for Empowerment, in C. Medel-Annonuevo (Ed.) Women, Education and Empowerment: pathways towards autonomy. Hamburg: UNESCO-UIE.

Stromquist, N. P. 2002. Education as a Means for Empowering Women, in Jane L. Parpart, Shirin M. Rai \& Kathleen A. Staudt (Eds) Rethinking Empowerment: gender and development in a global/local world, pp. 22-37. London: Routledge.

Taylor-Gooby. P., 2013. The double crisis of the Welfare State and what we can do about it, Basingstoke: Palgrave.

Thapar-Björkert, S., Samelius, L., and Sanghera, G. S. 2016. Exploring symbolic violence in the everyday: misrecognition, condescension, consent and complicity. Feminist Review, 112, 144-162.

Tronto, J. 1993. Moral boundaries: a political argument for an ethic of care, London: Routledge.

Turner, G. and Shepherd, J. 1999. A method in search of a theory: peer education and health promotion. Health Education Research, 14 (2), 235-247.

van Aar, J. V., Asscher, J. J., Zijlstra, B. J. H., Dekovič, M., Hoffenaar, P. J., 2015. Changes in parenting and child behaviour after the Home-Start family support program: a 10 year follow-up, Children and Youth Services Review, 53, 166-175.

Yar, M., 2001. Beyond Nancy Fraser's 'perspectival dualism'. Economy and Society, 30 (3), 288-303. 